\title{
Bundling innovations to transform agri-food
}

\section{systems}

\author{
Coupling technological advances with sociocultural and policy changes can transform agri-food systems to address \\ pressing climate, economic, environmental, health and social challenges. An international expert panel reports on \\ options to induce contextualized combinations of innovations that can balance multiple goals.
}

\author{
Christopher B. Barrett, Tim G. Benton, Karen A. Cooper, Jessica Fanzo, Rikin Gandhi, Mario Herrero, \\ Steven James, Mark Kahn, Daniel Mason-D'Croz, Alexander Mathys, Rebecca J. Nelson, \\ Jianbo Shen, Philip Thornton, Elizabeth Bageant, Shenggen Fan, Andrew G. Mude, \\ Lindiwe M. Sibanda and Stephen Wood
}

$\mathrm{T}$ he dramatic, global advances in human well-being ushered in by technological and institutional innovations in agri-food systems (AFS) over the past century increasingly appear unsustainable due to massive, adverse effects on climate, natural environment, public health and nutrition, and social justice. Contemporary AFS - encompassing the interlinked biophysical and human systems that span from agricultural production, through post-harvest manufacturing and distribution, to food consumption ${ }^{1}$ - were engineered primarily to boost productivity in delivering dietary energy supply sufficient to avoid famines in the face of human population growth. They succeeded fabulously in that goal. But tomorrow's needs are different. We must continue raising productivity while shifting course to accommodate other crucial objectives like poverty reduction, promoting healthy diets, mitigating the climate and extinction crises, and building resilience ${ }^{2,3}$.

The urgency of transforming AFS is irrefutable ${ }^{4}$. Our international expert panel concludes that we cannot wait decades to start the transition if we are to successfully turn the big ships of local and global AFS from their current, perilous course towards a coherent, just, well-integrated and sustainable food system (see Box 1).

How can, indeed must, humanity induce further beneficial innovations to transform AFS in order to sustain, even build upon, past gains, while making AFS healthier for all people and for the planet that must sustain us and future generations? A rich pipeline of emergent genetic, digital, agroecological, policy and other innovations offers the promise of addressing these serious threats ${ }^{5}$. Success is by no means assured, however.

The challenges and opportunities we face originate in human agency. Billions of individual food consumers, farmers, firm managers, and workers - collectively, AFS stakeholders - make food-related decisions and act multiple times each day, pursuing their own motives within constraints specific to each stakeholder's place, time and role. No one controls even important sub-systems, much less the whole. Rather, AFS are highly decentralized networks of stakeholders independently making decisions that have important economic, environmental, health and social repercussions for others. We must embrace the deep interdependence among stakeholders if we are to induce beneficial innovations. Making our AFS healthy, equitable, resilient and sustainable (HERS) will require substantial effort and investment to share gains and responsibility and to manage unavoidable trade-offs among multiple goals.

\section{AFS transformation principles}

A few key principles must underpin intentional AFS transitions.

Building socio-technical innovation bundles of mutually reinforcing technologies, policies, knowledge, social institutions and cultural norms is the first principle. For example, eliminating the mineral and vitamin deficiencies that harm more than two billion people will require context-specific combinations of new, biofortified crop varieties, supporting extension and commercial seed systems, industrial fortification of manufactured staples such as iodized salt or fortified flour, strengthened by effective regulatory enforcement, well-functioning markets that deliver accessible and affordable diverse diets, and school feeding and nutrition education programmes that foster healthy dietary choices. No single one of these will suffice nor work everywhere.
We need bundles for three reasons. First, the emblematic AFS technologies of every era - for example, hybrid seed and salt iodization roughly a century ago, Green Revolution and then transgenic cereal varieties in the late twentieth century would probably have failed to scale and achieve impact without less-celebrated, ancillary policies and sociocultural accelerators. Rural infrastructure, agricultural extension and secure land tenure were essential, as were adequate social protections for farmers or workers threatened by transformation ${ }^{5,6}$. Broad AFS stakeholder participation is essential to co-create the right bundle for a specific time and place.

The second reason to bundle is because single technologies inevitably involve trade-offs across multiple desirable objectives. For example, new methods of making meat substitutes may bring animal welfare, climate and environmental benefits. But if the production costs of plant-based and cellular substitutes fall to the point that they hurt livestock and feed crop producers, they also risk aggravating rural poverty. We could not identify a single AFS innovation likely to have no negative effects on one or more of the United Nations (UN) Sustainable Development Goals, which are specific, nearer-term representations of the HERS objectives ${ }^{7}$. Single-minded efforts to advance single goals or technologies therefore inevitably invite powerful, legitimate and costly opposition.

Third, single innovations typically yield incomplete gains. Complementary interventions are commonly needed to achieve broad-scale results, as in the previous example of combatting micronutrient deficiencies.

Reducing the land and water footprint of food production and consumption is the 
Box 1 | Expert panel on innovations to build sustainable, equitable and inclusive food value chains

The Cornell Atkinson Center for Sustainability and Nature Sustainability jointly convened an expert panel of 23 recognized experts from around the world, spanning many disciplines and organizations (https://blogs.cornell.edu/ nature-sustainability/). The panel first met in December 2019. Over the year it synthesized the best current scientific evidence to describe the present state and external drivers of the world's AFS, to assess emergent innovations, to articulate a shared vision for these systems 25-50 years hence, and to advise on how best to induce agri-food value chain actors to navigate together from the present state to that future vision through thoughtful bundling of distinct innovations ${ }^{15}$. The expert panel consisted of co-chairs Christopher B. Barrett (Cornell University), Tim Benton (Chatham House and University of Leeds), Jessica Fanzo (Johns Hopkins University), Mario Herrero (Commonwealth Scientific and Industrial Research Organisation) and Rebecca J. Nelson (Cornell University), with Edward Buckler (US Department of Agriculture Agricultural Research Service), Karen A. Cooper (Societé des Produits Nestlé SA), Karrie Denniston (Walmart. org), Shenggen Fan (China Agricultural University), Rikin Gandhi (Digital Green), Isatou Jallow (Africa Catalysing Action for Nutrition Network), Steven James (PepsiCo), Mark Kahn (Omnivore), Laté Lawson-Lartego (OXFAM America), Alexander Mathys (ETH Zurich), Andrew G. Mude (African Development Bank), Felix Preston (Generation Investment Management), Howard Yana-Shapiro (Mars, Inc.), Jianbo Shen (China Agricultural University), Lindiwe M. Sibanda (University of Pretoria), Roy Steiner (Rockefeller Foundation), Philip Thornton (International Livestock Research Institute) and Stephen Wood (The Nature Conservancy).

diets increase the willingness of consumers to pay for the health, social justice and sustainability attributes of food. A variety of fair trade, sustainability and other certification and labelling initiatives differentiate foods produced to higher standards, with varying degrees of success ${ }^{8-10}$. Activating and scaling that latent demand is not easy. It requires technological, regulatory, institutional and educational advances to enable low-cost, transparent, trusted verification and communication of food attributes to induce farmers and firms to internalize the adverse externalities AFS currently generate. Mobilizing latent consumer valuation of food attributes beyond convenience, price and taste, and overcoming other market failures, especially require digital advances ${ }^{11}$.

Projected demographic transitions necessitate greater focus on value chain intermediaries and on Africa. This fourth principle stems from two trends. First, $>65 \%$ of people will live in cities by 2050 . Post-farmgate value addition, which already accounts for nearly three-quarters of consumer food expenditures globally (J. Yi et al., manuscript in review), will therefore expand disproportionately quickly. Second, the vast majority of population growth to 2100 will occur in Africa, where half to three-quarters of global food demand growth to the end of the century will occur. Demographic and economic drivers necessitate greater investment in, and engagement with, mid-stream value chain and Africa-based actors to induce necessary AFS transitions.

Concentrated economic and political power too often impedes innovative policies or technologies (for example, carbon taxes, farm subsidies tied to conservation or renewable energy goals, use of gene editing or transgenic methods, and wealth taxes) and directly obstructs progress (for example, via catch-and-kill acquisitions, patent thickets, and political lobbying). Actively deconcentrating market and political power through (largely digital or policy) initiatives to enhance civic engagement and enforce anti-trust laws can accelerate beneficial innovation.

Communities of practice specific to each AFS must co-create locally contextualized socio-technical bundles. These begin with a commitment to shared value and responsibility, based on a common vision that galvanizes collective action to design mechanisms that direct individual actions towards beneficial innovation, to provide mutual insurance against losses in any one domain, and to identify key performance measures to enable adaptive management and monitoring and enforcement of agreed actions. This is feasible and impactful, as demonstrated at scale by China's Science and Technology Backyard experience that brings together millions of farmers with university-based researchers, government extension agents, private agro-input companies, and local land and water managers ${ }^{12}$.

AFS transformation requires considerable up-front investment. The COVID-19 pandemic demonstrated that governments and private firms can quickly mobilize massive funding when stakes are high and solutions are urgently needed ${ }^{13}$. Governments could crowd in considerable private investment in AFS transformations by redirecting the roughly US $\$ 2$ billion per day states now spend on farm subsidies ${ }^{14}-$ that largely damage the natural environment, reinforce income inequality and impede necessary innovations - toward social protection programmes, agri-food research and enabling physical and institutional infrastructure, including universal rural broadband access and effective regulatory oversight. A growing community of private investors, facing historically low interest rates and flush with cash, recognize the complementarities between longer-term financial and non-financial outcomes. Novel financial instruments - like landscape bonds - are emerging to facilitate investment in the socio-technical bundles needed to build HERS AFS.

Science-based possibilities abound. But diverse stakeholders must work specific agri-food production processes and 
cooperatively to identify and combine technological, sociocultural and policy innovations appropriate for each distinct AFS if we are to adjust course and steer away from looming climate, environmental, health, nutrition and social justice dangers and towards a HERS future ${ }^{15}$.

ChristopherB.Barrett (D) ${ }^{1 凶}$, Tim G. Benton (D) ${ }^{2,3}$, KarenA.Cooper ${ }^{4}$,JessicaFanzo ${ }^{5}$, RikinGandhi ${ }^{6}$, Mario Herrero (D)7, Steven James ${ }^{8}$, Mark Kahn ${ }^{9}$, Daniel Mason-D'Croz [D] 7 , Alexander Mathys (D) ${ }^{10}$, Rebecca J. Nelson', Jianbo Shen"11, Philip Thornton (iD)12, Elizabeth Bageant ${ }^{1}$, Shenggen Fan ${ }^{11}$, Andrew G. Mude ${ }^{13}$, Lindiwe M. Sibanda ${ }^{14}$ and Stephen Wood (D) 15

${ }^{1}$ Cornell University, Ithaca, NY, USA. ${ }^{2}$ University of Leeds, Leeds, UK. ${ }^{3}$ Chatham House, London, UK. ${ }^{4}$ Societé des Produits Nestlé SA, Vevey, Switzerland. ${ }^{5}$ Johns Hopkins University, Baltimore,
MD, USA. ${ }^{6}$ Digital Green, San Francisco, CA, USA. ${ }^{7}$ Commonwealth Scientific and Industrial Research Organisation, Brisbane, Queensland, Australia. ${ }^{8}$ PepsiCo, Dallas, TX, USA. ${ }^{9}$ Omnivore, Mumbai, India. ${ }^{10}$ ETH Zurich, Zurich, Switzerland. ${ }^{11}$ China Agricultural University, Beijing, China.

${ }^{12}$ International Livestock Research Institute, Nairobi, Kenya. ${ }^{13}$ African Development Bank, Abidjan, Côte d'Ivoire. ${ }^{14}$ University of Pretoria, Pretoria, South Africa. ${ }^{15}$ The Nature Conservancy, New Haven, CT, USA.

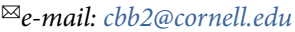

Published online: 10 December 2020

https://doi.org/10.1038/s41893-020-00661-8

References

1. McCullough, E. B., Pingali, P. L. \& Stamoulis, K. G. (eds) The Transformation of Agri-Food Systems: Globalization, Supply Chains and Smallholder Farmers (FAO, 2008).

2. Keating, B. A., Herrero, M., Carberry, P. S., Gardner, J. \& Cole, M. B. Glob. Food Secur. 3, 125-132 (2014).

3. Willett, W. et al. Lancet 393, 447-492 (2019).
4. Webb, P. et al. Nat. Food 1, 584-585 (2020).

5. Herrero, M. et al. Nat. Food 1, 266-272 (2020).

6. Barrett, C. B. Am. J. Agric. Econ. https://doi.org/10.1111/ ajae.12160 (in the press).

7. Herrero, M. et al. Lancet Planet. Health https://doi.org/10.1016/ S2542-5196(20)30277-1 (in the press).

8. Dragusanu, R., Giovannucci, D. \& Nunn, N. J. Econ. Perspect. 28 217-236 (2014).

9. Sunstein, C. R. Food Policy https://doi.org/10.1016/j. foodpol.2020.101984 (in the press).

10. Lambin, E. F. \& Thorlakson, T. Annu. Rev. Environ. Resour. 43 369-393 (2018).

11. Basso, B. \& Antle, J. Nat. Sustain. 3, 254-256 (2020).

12. Zhang, W. et al. Nature 537, 671-674 (2016).

13. Herrero, M. \& Thornton, P. K. Lancet Planet. Health 4, el74 (2020).

14. Agricultural Policy Monitoring and Evaluation 2020 (OECD, 2020).

15. Barrett, C. B. et al. Socio-Technical Innovation Bundles for Agri-Food Systems Transformation: Report of the International Expert Panel on Innovations to Build Sustainable, Equitable, Inclusive Food Value Chains (Cornell Atkinson Center for Sustainability and Springer Nature, 2020); https://www.nature com/documents/Bundles_agrifood_transformation.pdf

Competing interests

The authors declare no competing interests. 